\title{
The functional capacity and quality of life of women with advanced breast cancer
}

Kokkonen, K.

2017-01

Kokkonen , K, Saarto , T, Makinen , T, Pohjola , L, Kautio , H, Jarvenpaa , S \&

Puustjärvi-Sunabacka , K 2017 , ' The functional capacity and quality of life of women with advanced breast cancer ' , Breast Cancer , vol. 24 , no. 1 , pp. 128-136 . https://doi.org/10.1007/s12282-016-0687-2

http://hdl.handle.net/10138/232551

https://doi.org/10.1007/s12282-016-0687-2

publishedVersion

Downloaded from Helda, University of Helsinki institutional repository.

This is an electronic reprint of the original article.

This reprint may differ from the original in pagination and typographic detail.

Please cite the original version. 


\title{
The functional capacity and quality of life of women with advanced breast cancer
}

\author{
K. Kokkonen ${ }^{1}$ T. Saarto ${ }^{2}$ T. Mäkinen ${ }^{1}$ L. Pohjola ${ }^{1}$ H. Kautio ${ }^{3}$. \\ S. Järvenpääa ${ }^{4}$ K. Puustjärvi-Sunabacka ${ }^{1}$
}

Received: 18 January 2016/ Accepted: 3 March 2016/Published online: 22 March 2016

(c) The Japanese Breast Cancer Society 2016

\begin{abstract}
Background The rehabilitation needs of patients with metastatic breast cancer (MBC) are poorly studied. The primary aim of the study was to evaluate the functional capacity of women with MBC and quality of life (QoL). Methods The present study is an open, non-randomized, prospective cross-sectional observation study. The functional capacity of $128 \mathrm{MBC}$ patients with ongoing cancer treatments, were studied in Helsinki University Hospital (HUS): Peak expiratory flow (PEF), dynamic and static balance, 6 minute walking distance (6MWD), 10 meter walking, sit-to-stand test, repeated squat, grip strength, shoulder movement, pain, and QoL by Beck's depression scale (BDI), health assessment questionnaire (HAQ), RAND SF-36 and EORTC QLQ-30 items.

Results The walking capacity was compromised in half and the strength of the lower extremities in one-third of the patients. PEF was below the normal reference in $55 \%$, static balance in $62 \%$ and dynamic balance in $73 \%$ ( $\leq 60$ year olds) and $81 \%$ ( $\geq 61$ year olds). The grip power was lowered in $44 / 30 \%$ of the patients (right/left) and the
\end{abstract}

K. Kokkonen

kristiina.kokkonen@helsinki.fi

T. Saarto

tiina.saarto@hus.fi

1 Department of Physical Medicine and Rehabilitation, Helsinki University Central Hospital, Helsinki, Finland

2 Helsinki University Central Hospital, Cancer Center, University of Helsinki, P.O. Box 180, 00029 Helsinki, Finland

3 Unit of Family Practice, Central Finland Central Hospital, Jyväskylä, Finland

4 The Medcare Foundation, Äänekoski, Finland shoulder movement was restricted in $30 \%$. Some disability in physical functioning experienced $55 \%$ (HAQ) and $37 \%$ felt depressive (BDI). The QoL (RAND SF-36) was poor especially in the field of physical, role and social functioning and bodily pain $(<0.001)$. Pain, depression, and a poor 6MWD results independently determined the physical component of QoL $(p<0.001)$.

Conclusions The functional capacity of patients with MBC was significantly lowered. This, in association with distressing symptoms like pain and depression causes a vicious circle further leading to functional disabilities and impaired QoL.

Keywords Breast cancer - Disability - Metastatic . Quality of life · Rehabilitation

\section{Introduction}

In recent years, the survival of women with metastatic breast cancer (MBC) has improved because of the advances in cancer-specific therapies. According to a Canadian population based cohort study, a median survival of patients with MBC has improved from 15 to 22 months since 1991 [1]. Longer survival and multiple treatment options enable multiple lines of cancer treatments. Indeed, surveys of clinical practice in the USA suggest that women with advanced breast cancer receive an average of four to six lines of chemotherapy [2].

Progressive disease and multiple medical interventions cause mental stress and physical impairment including dysfunction of neuromuscular and skeletal structures [3]. For example, $70 \%$ of breast cancer patients with advanced disease have bone metastases causing significant pain and functional disability [4]. Compromised functional ability 
leads to physical inactivity [5, 6], which manifests as loss of muscle strength, impaired balance and fatigue affecting cancer patients' self-care and social activities. Thus, physical inactivity due to functional impairment may cause a vicious circle leading to a generalized weakness and impaired quality of life (QoL) [5, 7].

The aim of cancer patient's rehabilitation is to restore and improve functional abilities, physical independence, and thus maintain quality of life. Physical activity and exercise training of breast cancer patients with early stage of the disease and cancer survivors is shown to improve physical functioning, QoL and to reduce fatigue [8], but only limited evidence is found in patients with advanced cancer [9]. Yet, there is little evidence of the rehabilitation needs in advanced cancer [9].

The data of QoL of cancer patients with advanced disease is mainly based on new anticancer treatment interventions where QoL is not the primary objective [10]. According to questionnaire based on cross-sectional studies of QoL of patients with advanced disease, QoL is however, generally impaired and the symptom burden is a significant problem where pain, fatigue, and emotional distress being the leading problems $[11,12]$.

The present study is an open, non-randomized, prospective cross-sectional observation study with the primary objective to evaluate the functional capacity of women with advanced breast cancer during their chemotherapy treatment. The secondary endpoint is their quality of life.

\section{Patients and methods}

\section{Patients}

211 voluntary, consecutive females at the outpatient unit of HUS, Department of Oncology during the year 2009 participated in the study. The inclusion criteria were age 18 years or older, and ongoing treatment for metastatic breast cancer. Of 211 patients, 155 gave a written informed consent to participate. Later 27 patients canceled their appointment for physical testing because of unsuitable timetable or illness. Finally, 128 patients were tested. The overall recruitment rate was $61 \%$.

The local Ethical Committee of Helsinki University Hospital approved the study protocol. The trial has been registered in the Helsinki and Uusimaa Hospital District Clinical Trials Register (http://www.hus.fi) with the unique trial number 233307.

\section{Measures}

The physical functioning was tested by the same experienced physical therapist. The test pattern was selected in consideration of bone metastases not to predispose patients to a risk of trauma by high resistance or extreme ranges of movements in testing.

\section{Physical performance}

The respiratory function was evaluated by measuring the peak expiratory flow (PEF, 1/min) [13]. Three measurements were taken and the best value was chosen.

The dynamic balance was measured using 6 meter backwards-walking (walking speed) compared with the reference values of healthy women aged 31-60 [14]. The results are scaled from 1 (>31 s/poor) to 5 (<18 s/excellent), where 3 is a moderate/fair result. In the present study levels 4 and 5 were not tested, as they should have been performed on a block of wood. The static balance was tested using one foot stance (time in seconds) in two different ways (TOIMIVA and UKK tests). The age-related reference values were used for women aged 20-70 years [15] and 70-89 years [16] in TOIMIVA test, and from 25 to 60 years [17] in UKK test.

Two walking tests were performed: 10 meters walking at maximum speed [18] with reference values for normal population aged 13-80 years [19] and six minute walking distance (6MWD) test by using standardized formulas modulated by Enright and Sherrill [20]:

$$
\begin{aligned}
6 \mathrm{MWD}_{\text {predicted }}= & \left(2.11 \times \text { height }_{(\mathrm{cm})}\right) \\
& -\left(2.29 \times \text { weight }_{(\mathrm{cm})}\right)-(5.78 \times \text { age }) \\
& +667 \mathrm{~m}
\end{aligned}
$$

where LLN was (6MWD-139 m).

Sit-to-stand test was performed by recording the time taken for five repetitive stand up's from a sitting position [21]. The reference values for women aged from 55 to 80 were used [22]. In the repetitive squatting test, the patient squats and gets up at an even pace as many times as possible (up to 50 times). The reference values for women aged 35-54 were used [23].

The ROM of the shoulder joint was measured with a goniometer. The degrees were scaled from grade 1 to 5 and ranges from 3 to 5 were considered as normal/good for functioning [17]. The grip strength was measured with a dynamometer and the results were compared with reference values for Finnish adults [24].

\section{QoL and physical functioning}

The RAND SF-36-Item health survey evaluates general health and wellbeing in eight dimensions: experienced general health, physical functioning, role limitation due to physical health problems, or emotional problems, pain, 
general health perceptions, vitality, general mental health, subjective change of health status over the past year [25]. The four dimensions of RAND-36: experienced general health, physical functioning, role limitation due to the physical health problems and pain, were also aggregated into one summary measure, the physical component.

The 30-item EORTC QLQ-C30 health questionnaire is composed of five functioning scales (physical, role, emotional, cognitive and social), three symptom scales (nausea/ vomiting, pain and fatigue) and a scale of global QoL. In addition, the questionnaire contains six single items for assessing financial difficulties, dyspnoea, diarrhea, appetite loss, sleep disturbances, and constipation. High scores for functional scales and for a global health score represent a high/healthy level of functioning. High scores for symptom scales represent a higher level of symptoms [26]. Generally, a 10-point change or more has been considered to be clinically significant.

The patients filled the health assessment questionnaire (HAQ) to assess self-reported physical functioning in daily activities [27] including dressing and grooming, rising, eating, walking, hygiene, reach, grip, and community activities. It is expressed on a scale from 0 (no functional disability) to 3 (severe functional disability).

Depressive symptoms were assessed using the Finnish modified version of Beck's 13-item depression scale (BDI) [28]. The point sum measures the depth of the depression symptoms: $0-4$ points signifies no depressive symptoms, 5-7 mild, 8-15 moderate and 16-39 suggest severe depressive symptoms.

Pain at present, during movement, during the past week and the interference of pain during daily activities were measured by using a numeric rating scale (NRS) from 0 to 10 .

The medical history of the patients was surveyed, and the weight and height were measured so that body mass index (BMI, body weight in $\mathrm{kg} / \mathrm{square}$ of height in meters) was calculated.

\section{Statistical analyses}

The data is presented as means with standard deviations, medians with inter quartile ranges or as counts with percentages. The most important outcomes are given with 95 per cent confidence intervals, which were obtained by biascorrected bootstrapping (2000 replications) for the RAND36 dimensions. The Finnish general population values for the eight RAND-36 dimensions were weighted to match the age distribution of the study population. The comparisons between study patients and Finnish general population values in RAND-36 dimensions were made by a simulation-based $t$ test.

Analysis of variance, Kruskal-Wallis rank test or Chi square test was used to detect differences between three groups. The linearity was tested, by using analysis of covariance with an appropriate contrast and age as a covariate. In the case of dichotomous outcome a logistic regression was used. The factors associated to physical health component in RAND-36 were investigated by an ordered logistic regression models. The dependent variable, physical health component, was divided into tertiles, and both univariate and multivariate forward stepwise models were adapted.

\section{Results}

\section{Demographic data}

Demographic data was presented in Table 1. 43 patients (33.6 \%) had an ideal weight (BMI 18.5-24.9), 1 (0.8\%) was underweight (BMI <18.5), $52(40.6 \%)$ were overweight (BMI 25-30) and $32(25 \%)$ were obese (BMI $\geq 30$ ).

The median time elapsed from the primary diagnosis of breast cancer was 6 years (0-20 years) and the time from the primary diagnosis to that of the metastases was median to 3 years $(0-12$ years). The metastases located in the skeleton $(N=95,74.2 \%)$, liver $(N=60,46.9 \%)$, lungs $(N=32,25.0 \%)$, brain $(N=11,8.6 \%)$ and in various other organs $(N=48,37.5 \%)$. Seventy nine patients $(61.7 \%)$ had multiple sites of metastases.

\section{Treatments}

A total of 62 patients $(48.4 \%)$ had undergone surgery of the right breast, 71 patients $(55.5 \%)$ had prior surgery of the left breast, $13(10.2 \%)$ had received bilateral breast surgery, and in 8 women $(6.3 \%)$ the primary tumor of the breast had not been managed surgically.

The most common chemotherapy agents used were docetaxel $(N=100,78 \%)$, anthracycline $(N=40,31 \%)$, paclitaxel $(N=27,21 \%)$, capecitabine $(N=23,18 \%)$, vinorelbine $(N=15,12 \%)$ and gemcitabine $(N=13$, $10 \%)$. The mean number of chemotherapy lines were 2 (range 1-7); $42 \%$ had first line chemotherapy; $25 \%$ second; $15 \%$ third; $13 \%$ fourth to seventh line. Ninety patients $(70 \%)$ were treated with endocrine therapies; aromatase inhibitors $83(65 \%)$ and tamoxifen 37 patients $(29 \%)$. Trastuzumab was used in 46 women of 128 (36\%).

Reviewed approximately after a year later in July 2010, 27 patients $(21 \%)$ had died.

\section{Physical functioning}

The main results concerning physical performance are represented in Table 1. 
Table 1 The characteristics of patients and physical performance

\begin{tabular}{|c|c|c|c|c|c|c|}
\hline Variable & $N($ tested $\%)$ & Result (mean) & SD & Range & Normal $N(\%)$ & Lowered $N(\%)$ \\
\hline Age (years) & 128 & 60 & & $34-84$ & & \\
\hline BMI & 128 & 27.2 & 5 & $16-44$ & & \\
\hline Multiple metastases & $79(62)$ & & & & & \\
\hline Chemotherapy (IQR) & $122(95)$ & & & & & \\
\hline \multicolumn{7}{|l|}{ Physical functioning } \\
\hline PEF (L/min) & $128(100)$ & 377 & 84 & $200-590$ & $58(45)$ & $70(55)$ \\
\hline Dynamic balance ( $\leq 60$ years) $(\mathrm{s} / 6 \mathrm{~m})$ & $62(48)$ & & & $16.4-50.0$ & $17(27)$ & $45(73)$ \\
\hline Dynamic balance ( $\geq 61$ years) $(\mathrm{s} / 6 \mathrm{~m})$ & $59(46)$ & & & $16.4-50.0$ & $11(19)$ & $48(81)$ \\
\hline Static balance, UKK ( $\leq 60$ years) $(\mathrm{s} / 60 \mathrm{~s})$ & $62(48)$ & 37.3 & 23 & $0-60$ & $34(55)$ & $26(42)$ \\
\hline Static balance, TOIMIVA (61-69 years) $(\mathrm{s} / 60 \mathrm{~s})$ & $37(29)$ & 20.3 & 9.6 & $0-60$ & $14(38)$ & $23(62)$ \\
\hline Static balance, TOIMIVA ( $\geq 70$ years) $(\mathrm{s} / 60 \mathrm{~s})$ & $18(14)$ & 12.5 & 10 & $0-60$ & $7(39)$ & $11(61)$ \\
\hline $10 \mathrm{~m}$ walking time (all age groups) (s) & $128(100)$ & 6.1 & 2 & $3.7-14.6$ & & \\
\hline $10 \mathrm{~m}$ walking time $(\leq 60$ years $)(\mathrm{s})$ & $56(44)$ & 5.2 & 1 & & & \\
\hline $10 \mathrm{~m}$ walking time ( $\geq 61$ years) $(\mathrm{s})$ & $72(56)$ & 6.7 & 2.3 & & $30(42)$ & $42(58)$ \\
\hline 6 MWD (m) & 111(87) & 426 & 194 & $0-710$ & $55(50)$ & $56(50)$ \\
\hline Sit-to-stand (all age groups) (s) & $128(100)$ & 13.8 & 6.6 & $7.1-57.0$ & & \\
\hline Sit-to-stand ( $\geq 55$ years) (s) & $93(73)$ & 14.5 & 7 & $7.1-33.8$ & $65(70)$ & $28(30)$ \\
\hline Repeated squat ( $\leq 55$ years) (number of squats) & $44(34)$ & 9 & 14 & $0-50$ & $12(27)$ & $32(73)$ \\
\hline Shoulder movement (grade $1-5$ ) & $128(100)$ & 3 & 1.4 & $1-5$ & $90(70)$ & $38(30)$ \\
\hline Grip strength, right arm (kg) & $128(100)$ & 24.7 & 6.5 & $0-40$ & $72(56)$ & $56(44)$ \\
\hline Grip strength, left arm (kg) & $128(100)$ & 23.6 & 6.3 & $0-38$ & $89(70)$ & $39(30)$ \\
\hline \multicolumn{7}{|l|}{ Symptoms } \\
\hline Pain intensity (NRS $1-10)^{\mathrm{a}}$ & $121(95)$ & 3.90 & 2.9 & $0-10$ & $21(17)$ & $100(83)$ \\
\hline Pain in movement (NRS $1-10)^{\mathrm{a}}$ & $127(99)$ & 3.2 & 3 & $0-10$ & $55(43)$ & $72(57)$ \\
\hline Disability caused by pain (NRS $1-10)^{\mathrm{a}}$ & $126(98)$ & 4.4 & 3.2 & $0-10$ & $24(19)$ & $102(81)$ \\
\hline Physical functioning (HAQ) $(1-3)^{\mathrm{b}}$ & $128(100)$ & 0.35 & 0.4 & $0-1.9$ & $58(45)$ & $70(55)$ \\
\hline Depression $(\mathrm{BDI})^{\mathrm{c}}$ & $119(93)$ & 4.3 & 3.6 & $0-18$ & $75(63)$ & 44 (37) \\
\hline
\end{tabular}

The correlation between QoL and the functional capacity is presented in tertiles according to the level of physical quality of life

${ }^{\text {a }}$ Normal $=$ free of pain

b Normal $=0$

c Normal $=0-4$

In the age group $\leq 61$ years, the dynamic balance was low in $73 \%$ and the static balance was low in $42 \%$ (Table 1). Among the patients aged $>60$ years, the static balance was poor in $55 \%$, and $73 \%$ did not even manage to complete the dynamic balance test (Table 1). Both dynamic $(p=0.0018)$ and static $(p=0.001)$ balance correlated positively with the physical component of QoL (Fig. 1).

The sit-to-stand time was extended in $30 \%$ of patients $\geq 55$ years. More than half of the patients could not perform the test as it was too demanding. The repeated squatting test was lowered in $73 \%$ of the patients in age group $\leq 55$ years where $43 \%$ could not perform any squats (Table 1 ).

The right arm was dominant in 120 and the left in 8 patients. The grip strength was below normal in $43.8 \%$ on the right and in $30.5 \%$ on the left upper arm. It was symmetrical in 98 patients $(76.6 \%)$ (Table 1$)$. The shoulder movement was symmetrical in 107 patients $(83.6 \%)$. Of patients with restricted ROM, $27(21.1 \%)$ had grade 1 movement, $11(8.6 \%)$ had grade 2, 54 $(42.2 \%)$ grade $3,6(4.7 \%)$ grade 4 and $30(23.4 \%)$ grade 5 movement. Of 21 patients with asymmetric movement, the operated side of 19 patients $(90 \%)$ was worse.

\section{Symptoms}

In EORTC-C30 questionnaire, majority of the patients reported symptoms as fatigue ( $95 \%$, moderate or severe $\mathrm{N} 23 \%$ ), pain (83 and $21 \%$ ) and insomnia (58 and $20 \%$ ), dyspnea (41 and $8 \%$ ), constipation (38 and $17 \%$ ), appetite loss (37 and $17 \%)$, diarrhea (28 and $3 \%$ ) and nausea/ vomiting (27 and $3 \%$ ). 


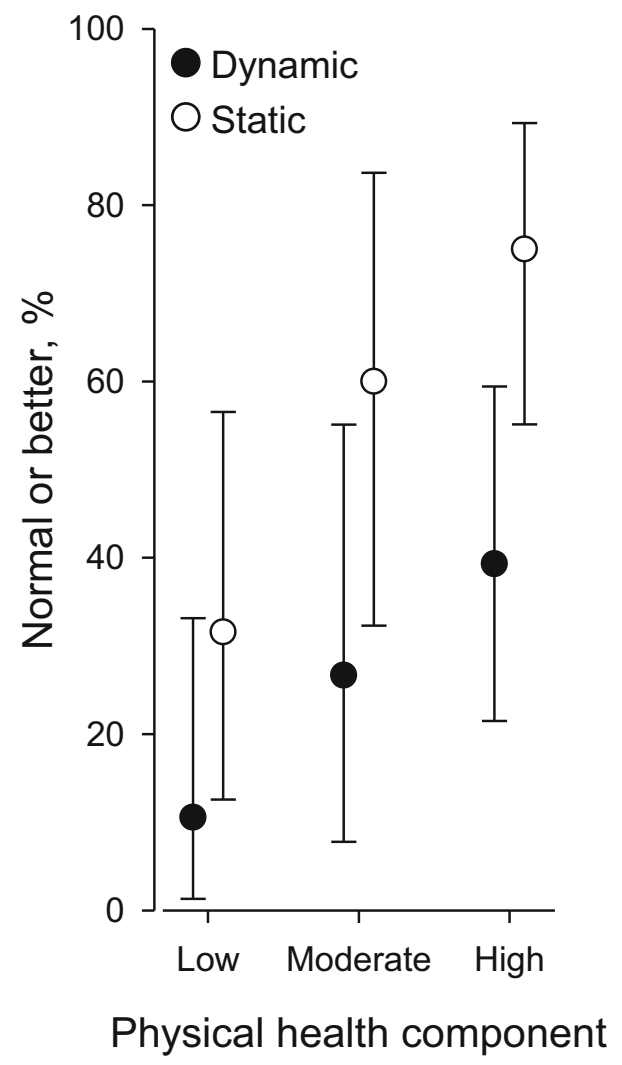

Fig. 1 Proportions of patients having normal or better result in balance tests according to physical component tertiles. Patients under 61 years were included

The mean intensity of pain during the previous week was 3.9 (SD 2.9). Twenty one patients (17.4\%) reported no pain. Experienced pain was mild (1-3) in 38 patients $(31.4 \%)$, moderate $(4-5)$ in 28 patients $(23.1 \%)$, severe $(6-7)$ in 18 patients $(14.9 \%)$ and very severe $(8-10)$ in 16 patients $(13.2 \%)$ (Table 1$)$.

\section{QoL}

All patients responded to the RAND SF-36 questionnaire. Patients in this study had significantly lower values in general health perceptions [43.1 (SD 18.5)], bodily pain [59.7 (SD 25.6)], physical functioning [59.6 (SD 26.7)], role functioning [33.6 (SD 40.2)], social functioning [68.5 (SD 26.6)] and in vitality [55.3 (SD 22.0)]; no differences were found in mental health [73.4 (SD 17.9)] or emotional role functioning [60.2 (SD 44.7)] as compared to general Finnish population (Fig. 2).

The EORTC QLQ-C30 functional scores were generally lower compared to healthy population (Table 2).

Almost half of the patients reported some minor difficulties in self-assessment of physical functioning measured by HAQ.

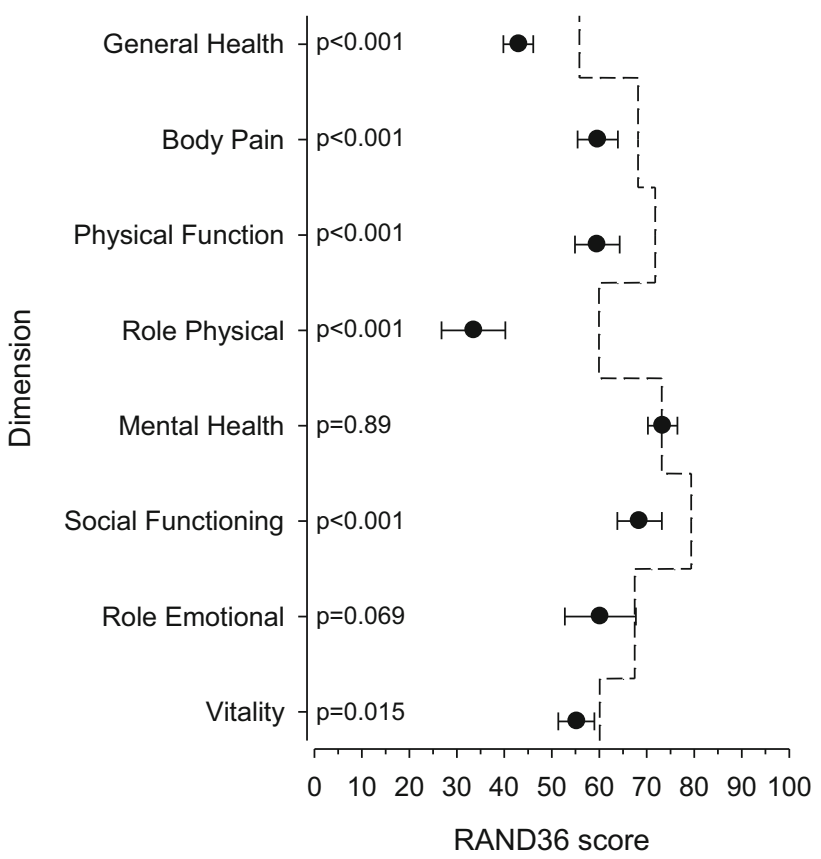

Fig. 2 The scores for the functional scales of RAND SF-36 (means with $95 \%$ CIs) in study population. The dashed line shows the scores in the general Finnish population weighted to match the age of the study population

Depressive mood was defined in $37 \%$ of the patients. From these patients, 25 had mild, 17 moderate and 2 had severe depressive disorders (Table 1).

\section{Factors associated with the physical component of quality of life}

Patients age adjusted with the physical performance was presented according to three tertiles of the RAND-36 physical component in Table 3. In univariate analysis, depression, pain, poor 10 meters walking speed, 6MWD, poor sit-to-stand test time and older age correlated with the impaired physical component of QoL; in forward stepwise ordered logistic regression analysis, depression, pain and 6MWD appeared to be the most important determinants of the physical component of QoL (Table 4).

\section{Discussion}

In the present prospective observational study, we found significant impairments in physical functioning of women with metastatic breast cancer during their cancer chemotherapy. Quality of life (QoL) was also most significantly impaired in the area of role physical functioning. In fact, impaired physical functioning (muscle strength and exercise capacity), depression and pain were the only 
Table 2 The functional scores from 0 to 100 from the EORTC QLQ-C30 for study population and for the Swedish general population [40]

\begin{tabular}{llllll}
\hline & \multicolumn{2}{l}{ Study population $(N=128)$} & & \multicolumn{2}{l}{ Swedish general population $(N=1616)$} \\
\cline { 2 - 3 } & Mean & SD & & Mean & SD \\
\hline Global health status & 61.5 & 20.38 & & 74.7 & 22.2 \\
Physical function & 64.9 & 22.10 & & 88.0 & 17.7 \\
Role function & 68.2 & 26.45 & & 86.0 & 24.4 \\
Emotional function & 79.3 & 18.39 & & 78.3 & 21.9 \\
Cognitive function & 83.1 & 20.05 & & 88.5 & 17.7 \\
Social function & 78.2 & 23.71 & & 90.4 & 19.6 \\
\hline
\end{tabular}

Table 3 Characteristics of patients and physical performance according to the tertiles of the RAND-36 physical component, adjusted by age

\begin{tabular}{|c|c|c|c|c|c|}
\hline \multirow[t]{2}{*}{ Variable } & \multicolumn{3}{|c|}{ Physical component of QoL, tertiles } & \multirow[t]{2}{*}{$p$ value } & \multirow[t]{2}{*}{ All $(N=128)$} \\
\hline & Low $(N=43)$ & Moderate $(N=41)$ & $\operatorname{High}(N=44)$ & & \\
\hline Age, years, mean (SD) & $62(12)$ & $62(10)$ & $57(11)$ & 0.036 & 60 \\
\hline BMI, mean (SD) & $27.5(5.4)$ & $27.0(4.7)$ & $27.1(4.9)$ & 0.88 & $27.1(4.9)$ \\
\hline Multiple metastases, $n(\%)$ & $27(63)$ & $27(66)$ & $25(57)$ & 0.68 & $79(62)$ \\
\hline Chemotherapy, median (IQR) & $2(1,2)$ & $1(1,3)$ & $2(1,3)$ & 0.93 & \\
\hline \multicolumn{6}{|l|}{ Physical functioning } \\
\hline PEF, 1/min, mean (SD) & $349(89)$ & $385(88)$ & $396(69)$ & 0.057 & $377(84)$ \\
\hline Normal or better, $n(\%)$ & $15(35)$ & $20(49)$ & $23(52)$ & & $58(45)$ \\
\hline \multicolumn{6}{|l|}{ 10-meter walking test, $\mathrm{s}$} \\
\hline ALL, mean (SD) & $7.3(2.5)$ & $5.7(1.6)$ & $5.1(1.0)$ & $<0.001$ & $6.1(2.0)$ \\
\hline$\geq 60$ years, mean $(\mathrm{SD})(n=72)$ & $8.2(2.7)$ & $6.1(1.8)$ & $5.6(1.1)$ & $<0.001$ & $6.7(2.3)$ \\
\hline$\geq 60$ years, normal or better, $n(\%)$ & $7(27)$ & $14(50)$ & $9(50)$ & & $30(42)$ \\
\hline 6 min walking time, $\mathrm{m}$, mean (SD) & $315(212)$ & 463 (177) & $499(140)$ & $<0.001$ & $426(194)$ \\
\hline$\geq$ Lower limit of normal (LLN), $\mathrm{n}(\%)$ & $25(58)$ & $35(85)$ & $40(91)$ & & $100(78)$ \\
\hline \multicolumn{6}{|l|}{ Sit-to-stand test, s } \\
\hline ALL, mean (SD) & $16.9(8.8)$ & $13.3(4.9)$ & $11.3(3.7)$ & $<0.001$ & $13.8(6.6)$ \\
\hline$\geq 55$ years, mean $(\mathrm{SD})(n=93)$ & $18.1(9.5)$ & $13.5(5.1)$ & $12.3(4.2)$ & 0.0049 & $14.6(7.0)$ \\
\hline Normal or better ( $\geq 55$ years), $n(\%)$ & $15(50)$ & $28(78)$ & $22(81)$ & & $65(70)$ \\
\hline \multicolumn{6}{|l|}{ Shoulder movement, range } \\
\hline Normal or better, $n(\%)$ & $23(53)$ & $30(73)$ & $37(84)$ & 0.0019 & $90(70)$ \\
\hline \multicolumn{6}{|l|}{ Grip strength, kg } \\
\hline Right upper extremity & $23.3(6.2)$ & $24.7(5.5)$ & $26.0(7.3)$ & 0.048 & $24.7(6.5)$ \\
\hline Normal or better, $n(\%)$ & $24(56)$ & $23(56)$ & $25(57)$ & & $72(56)$ \\
\hline Left upper extremity & $21.4(6.5)$ & $23.6(5.7)$ & $25.9(6.0)$ & 0.0089 & $23.6(6.3)$ \\
\hline Normal or better, $n(\%)$ & $24(56)$ & $32(78)$ & $33(75)$ & & $89(70)$ \\
\hline \multicolumn{6}{|l|}{ Symptoms } \\
\hline Pain NRS score, mean (SD) & $6.0(2.6)$ & $3.7(2.6)$ & $2.2(2.1)$ & $<0.001$ & $3.9(2.9)$ \\
\hline BDI score, mean (SD) & $6.3(4.3)$ & $4.1(2.5)$ & $2.4(2.5)$ & $<0.001$ & $27.2(5)$ \\
\hline
\end{tabular}

independent factors negatively associated with the physical component of QoL.

The rehabilitation needs of patients with advanced cancer are poorly recognized and inadequately met. As demonstrated by Cheville et al., various physical impairments were identified in more than $90 \%$ of 163 patients with advanced breast cancer [3]. However, physical impairments are only a part of the burden, which threatens the functioning and QoL of cancer patients with advanced disease. Distressing symptoms like pain and fatigue together with total number of functional impairments accounted for up to two-thirds of the variance in functional outcomes [9]. This is in line with our observation, where, in addition to impaired physical functioning, distressing symptoms 
Table 4 Univariate and multivariate stepwise ordered logistic regression models for the RAND-36 physical health component

\begin{tabular}{|c|c|c|c|c|}
\hline Variables & $\begin{array}{l}\text { Univariate }^{\mathrm{a}} \\
\text { OR }(95 \% \mathrm{CI})\end{array}$ & $p$ value & $\begin{array}{l}\text { Multivariate }{ }^{\mathrm{b}} \\
\text { OR }(95 \% \mathrm{CI})\end{array}$ & $p$ value \\
\hline Age & $0.96(0.93-0.99)$ & 0.016 & & \\
\hline BMI & $0.98(0.92-1.04)$ & 0.51 & & \\
\hline Multiple metastases & $0.78(0.40-1.52)$ & 0.47 & & \\
\hline Given chemotherapy lines & $1.14(0.89-1.45)$ & 0.30 & & \\
\hline Sit-to-stand test & $0.86(0.78-0.94)$ & $<0.001$ & & \\
\hline Grip strength, normal or better (dominant hand) & $1.03(0.97-1.10)$ & 0.28 & & \\
\hline 6MWD & $1.00(1.00-1.01)$ & $<0.001$ & $1.01(1.00-1.01)$ & $<0.001$ \\
\hline 10-meter walking time & $0.54(0.41-0.72)$ & $<0.001$ & & \\
\hline Pain NRS score & $0.65(0.56-0.75)$ & $<0.001$ & $0.63(0.53-0.76)$ & $<0.001$ \\
\hline BDI score & $0.70(0.61-0.80)$ & $<0.001$ & $0.70(0.59-0.82)$ & $<0.001$ \\
\hline
\end{tabular}

Dependent variable is divided into tertiles

$O R$ odds ratio

a Adjusted with age

${ }^{\mathrm{b}}$ Forward stepwise logistic regression model; only variables entered the model are shown

like pain and depression were independently associated with the physical component of QoL.

\section{Functional impairment}

Impaired muscle strength of the lower extremities and walking ability are storing indicators of functional impairments. In the present study, the muscle strength and endurance of the lower extremities were reduced in at least every third patient and the walking ability in more than every second patient. This is in line with Chevillés previous observation, where approximately half of the patients had lowered muscle strength and one-third of the physical impairments were exertional [9]. In addition, in our study, the majority of the patients had poor balance, especially dynamic balance $(78.1 \%)$. Balance is generally strongly related to the muscle strength of the lower extremities. However, neurotoxic chemotherapy agents, especially taxanes, were widely used in the treatment of our patients which are known to cause peripheral neuropathy [29]. Impaired muscle strength together with peripheral neuropathy can significantly impair balance and walking ability, and thus increase the risk of falls [30].

As the muscle strength of the lower extremities and walking ability reflect functional impairments, the grip strength is associated with general frailty and mobility limitations [31]. In breast cancer patients, impaired grip strength could also be related to previous axillary operation and radiotherapy. However, in the present population, the bilateral impairment of grip strength seemed to reflect general frailty rather than a consequence of surgery and radiotherapy.

\section{Functional disability}

The physical impairments begin to develop quite early during the illness trajectory. Loss of the ability to perform at least one activity of daily living (ADL) is seen already 12 months before death especially in frail people [32]. In the present study, more than half of the patients reported some functional disabilities despite of the relatively good life expectancy. Similar to the present study, Cheville reported a significant number of patients with some functional disability, and one-third of the patients were described as moderately disable [9]. However, to discover the rehabilitation needs, screening disabilities do not address the cause of the inability to rehabilitate. Using the common functional scales is also problematic as ceiling effect limits the discriminatory capacity of these scales [33]. Therefore, measuring the physical impairments could be more informative for planning rehabilitation.

\section{Symptoms}

Impaired physical functioning and cancer or treatment related symptoms are interrelating. Distressing symptoms could further reduce patient's functional capacity and impair QoL. In line with the previous literature, fatigue, pain and insomnia were the most common symptoms in the present population [34]. Fatigue is an activity limiting symptom [7] that affects cancer patients' functional capacity [35]. Fatigue has a strong influence on QoL and especially interferes with role functioning [35]. In addition to fatigue, more than half of our patients experienced pain during movement, which may further decrease physical 
activity. Hence, we found pain as one of the most significant variable influencing on physical component of QoL.

\section{QoL}

In the present study, the patients experienced significantly lowered QoL as compared to the general population, especially in physical, role and social functioning. This became evident with all instruments used, including generic (RAND SF-36) and disease specific (EORTCC30) surveys. This is in line with the previous studies of advanced and localized breast cancer [11, 12]. In early stage of the disease, QoL is generally less significantly impaired than in advanced cancer, but the functioning's most affected are equal $[11,12]$. Thus, patient's ability to function seems to be the key element of cancer patients QoL. Despite of less significantly impaired emotional functioning; the prevalence of depression in the present study population (37\%) was significantly higher than the prevalence in the general population in Finland (from 4.9 to $9.3 \%$ ) [36], and within patients with early stage breast cancer $(25.7 \%)$ [35]. This is in line with the previous studies, where the rate of depression and other psychological morbidities in breast cancer patients seems to be highest among severely ill and hospitalized patients (up to $40 \%$ ) [37, 38]. Mood disorders could further worsen physical symptoms and increase the risk of poor physical functioning [39]. In the present study, impaired functional ability, depression and pain appeared to be the most important determinants for the physical component of QoL [35].

Our study has several limitations. Firstly, the recruitment rate was somewhat low $(61 \%)$. It is possible that the most vulnerable patients or patients most emotionally distressed did not participate. This, however, would rather have underestimated than overestimated the functional impairments and impaired QoL of the population. Secondly, the physical function tests used were not planned and validated, particularly for cancer patients with advanced disease. The lack of age-matched reference values for all age groups further complicated the conclusions. Thirdly, we did not perform a physical examination or analyze the relationship between metastatic lesions and functional impairments in individual patients.

In summary, the present study indicates that the general functional capacity and QoL of breast cancer patients with metastatic disease are significantly lowered. Impaired physical functioning together with activity limiting symptoms, like pain, fatigue and depression can cause a vicious circle further impairing physical capacity and QoL, leading to functional disabilities. Pain, depression, impaired muscle strength and exercise capacity, were independently associated with reduced physical component of QoL. Systematic screening of adverse symptoms and a simple tests of physical functioning like the sit-to-stand test (muscle strength) might help the healthcare professionals to identify the patients in the greatest need of rehabilitative interventions. Exercise improves physical functioning, mood and the feeling of fatigue, and thus improves the QoL of cancer patients with local disease. Further, prospective controlled studies are needed to assess the benefits of exercise and physical rehabilitation in cancer patients with advanced disease.

Acknowledgments The study was financed by Helsinki University Central Hospital.

\section{Compliances with ethical standards}

Conflict of interest The authors declare that there is no conflict of interest.

\section{References}

1. Chia SK, Speers CH, D'yachkova Y, Kang A, Malfair-Taylor S, Barnett $J$, et al. The impact of new chemotherapeutic and hormone agents on survival in a population-based cohort of women with metastatic breast cancer. Cancer. 2007;110:973-9.

2. Lin NU, Burstein HJ. EMBRACE, eribulin, and new realities of advanced breast cancer. Lancet. 2011;377:878-80.

3. Cheville AL, Troxel AB, Basford JR, Kornblith AB. Prevalence and treatment patterns of physical impairments in patients with metastatic breast cancer. J Clin Oncol. 2008;26:2621-9.

4. Andre F, Slimane K, Bachelot T, Dunant A, Namer M, Barrelier $\mathrm{A}$, et al. Breast cancer with synchronous metastases: trends in survival during a 14-year period. J Clin Oncol. 2004;22:3302-8.

5. Fialka-Moser V, Crevenna R, Korpan M, Quittan M. Cancer rehabilitation: particularly with aspects on physical impairments. J Rehabil Med. 2003;35:153-62.

6. Fulton C. Patients with metastatic breast cancer: their physical and psychological rehabilitation needs. Int $\mathrm{J}$ Rehabil Res. 1999;22:291-301.

7. Stricker CT, Drake D, Hoyer KA, Mock V. Evidence-based practice for fatigue management in adults with cancer: exercise as an intervention. Oncol Nurs Forum. 2004;31:963-76.

8. Ferrer RA, Huedo-Medina TB, Johnson BT, Ryan S, Pescatello LS. Exercise interventions for cancer survivors: a meta-analysis of quality of life outcomes. Ann Behav Med. 2011;41:32-47.

9. Cheville AL, Kornblith AB, Basford JR. An examination of the causes for the underutilization of rehabilitation services among people with advanced cancer. Am J Phys Med Rehabil. 2011;90:S27-37.

10. Adamowicz K, Jassem J, Katz A, Saad ED. Assessment of quality of life in advanced breast cancer. An overview of randomized phase III trials. Cancer Treat Rev. 2012;38:554-8.

11. Aranda S, Schofield P, Weih L, Yates P, Milne D, Faulkner R, et al. Mapping the quality of life and unmet needs of urban women with metastatic breast cancer. Eur J Cancer Care. 2005; $14: 211-22$.

12. Kim EJ, Ko SK, Kang HY. Mapping the cancer-specific EORTC QLQ-C30 and EORTC QLQ-BR23 to the generic EQ-5D in metastatic breast cancer patients. Qual Life Res. 2012;21: 1193-203. 
13. Nunn AJ, Gregg I. New regression equations for predicting peak expiratory flow in adults. BMJ. 1989;298:1068-70.

14. Hamalainen HP, Suni JH, Pasanen ME, Malmberg JJ, Miilunpalo SI. Predictive value of health-related fitness tests for self-reported mobility difficulties among high-functioning elderly men and women. Aging Clin Exp Res. 2006;18:218-26.

15. Bohannon RW, Larkin PA, Cook AC, Gear J, Singer J. Decrease in timed balance test scores with aging. Phys Ther. 1984;64:1067-70.

16. Pohjola L. TOIMIVA tests in estimation on functional capacity of men over 75 years. 2006.

17. Suni JH, Oja P, Laukkanen RT, Miilunpalo SI, Pasanen ME, Vuori IM, et al. Health-related fitness test battery for adults: aspects of reliability. Arch Phys Med Rehabil. 1996;77:399-405.

18. Bohannon RW. Comfortable and maximum walking speed of adults aged 20-79 years: reference values and determinants. Age Ageing. 1997;26:15-9.

19. Whittle MW. An introduction to gait analysis. In: David Levine JR, editor. 5th ed. Oxford: Butterworth-Heinemann; 2012.

20. Enright PL, Sherrill DL. Reference equations for the six-minute walk in healthy adults. Am J Crit Care Med. 1998;158:1384-7.

21. Guralnik JM, Ferrucci L, Simonsick EM, Salive ME, Wallace RB. Lower-extremity function in persons over the age of 70 years as a predictor of subsequent disability. $N$ Engl $\mathrm{J}$ Med. 1995;332:556-61.

22. Aromaa A, Koskinen S. Terveys ja toimintakyky Suomessa. Terveys 2000-tutkimuksen perustulokset. Terveys 2000. Kansanterveyslaitoksen julkaisuja 2002;B3.

23. Alaranta H, Hurri H, Heliovaara M, Soukka A, Harju R. Nondynamometric trunk performance tests: reliability and normative data. Scand J Rehabil Med. 1994;26:211-5.

24. Harkonen R, Piirtomaa M, Alaranta H. Grip strength and hand position of the dynamometer in 204 Finnish adults. J Hand Surg Br. 1993;18:129-32.

25. Hays RD, Sherbourne CD, Mazel RM. The RAND 36-item health survey 1.0. Health Econ. 1993;2:217-27.

26. Aaronson NK, Ahmedzai S, Bergman B, Bullinger M, Cull A, Duez NJ, et al. The European organization for research and treatment of cancer QLQ-C30: a quality-of-life instrument for use in international clinical trials in oncology. J Natl Cancer Inst. 1993;85:365-76.

27. Fries JF, Spitz P, Kraines RG, Holman HR. Measurement of patient outcome in arthritis. Arthritis Rheum. 1980;23:137-45.

28. Beck AT, Rial WY, Rickels K. Short form of depression inventory: cross-validation. Psychol Rep. 1974;34:1184-6.
29. Kautio AL, Haanpaa M, Kautiainen H, Kalso E, Saarto T. Burden of chemotherapy-induced neuropathy - a cross-sectional study. Support Care Cancer. 2011;19:1991-6.

30. Sylliaas H, Thingstad P, Wyller TB, Helbostad J, Sletvold O, Bergland A. Prognostic factors for self-rated function and perceived health in patient living at home three months after a hip fracture. Disabil Rehabil. 2012;34:1225-31.

31. Sallinen J, Stenholm S, Rantanen T, Heliovaara M, Sainio P, Koskinen S. Hand-grip strength cut points to screen older persons at risk for mobility limitation. J Am Geriatr Soc. 2010;58:1721-6.

32. Lunney JR, Lynn J, Foley DJ, Lipson S, Guralnik JM. Patterns of functional decline at the end of life. JAMA. 2003;289:2387-92.

33. Cheville AL, Basford JR, Troxel AB, Kornblith AB. Performance of common clinician- and self-report measures in assessing the function of community-dwelling people with metastatic breast cancer. Arch Phys Med Rehabil. 2009;90:2116-24.

34. Teunissen SC, Wesker W, Kruitwagen C, de Haes HC, Voest EE, de Graeff A. Symptom prevalence in patients with incurable cancer: a systematic review. J Pain Symptom Manage. 2007;34:94-104.

35. Penttinen HM, Saarto T, Kellokumpu-Lehtinen P, Blomqvist C, Huovinen R, Kautiainen $\mathrm{H}$, et al. Quality of life and physical performance and activity of breast cancer patients after adjuvant treatments. Psychooncology. 2011;20:1211-20.

36. Pirkola SP, Isometsa E, Suvisaari J, Aro H, Joukamaa M, Poikolainen K, et al. DSM-IV mood-, anxiety- and alcohol use disorders and their comorbidity in the Finnish general population-results from the Health 2000 Study. Soc Psychiatry Psychiatr Epidemiol. 2005;40:1-10.

37. Kim SH, Son BH, Hwang SY, Han W, Yang JH, Lee S, et al. Fatigue and depression in disease-free breast cancer survivors: prevalence, correlates, and association with quality of life. J Pain Symptom Manage. 2008;35:644-55.

38. Fann JR, Thomas-Rich AM, Katon WJ, Cowley D, Pepping M, McGregor BA, et al. Major depression after breast cancer: a review of epidemiology and treatment. Gen Hosp Psychiatry. 2008;30:112-26.

39. van Milligen BA, Lamers F, de Hoop GT, Smit JH, Penninx BW. Objective physical functioning in patients with depressive and/or anxiety disorders. J Affect Disord. 2011;131:193-9.

40. Michelson H, Bolund C, Nilsson B, Brandberg Y. Health-related quality of life measured by the EORTC QLQ-C30-reference values from a large sample of Swedish population. Acta Oncol. 2000;39:477-84. 